\title{
Comparative Evaluation of Microtensile Bond Strength of Three Restorative Materials
}

\author{
Zohreh Ahangari ${ }^{1(\mathbb{D})}$, Effat Khodadadi ${ }^{2, *(\mathbb{D})}$, Fariba Ezoji ${ }^{3(\mathbb{D})}$, Soraya Khafri ${ }^{3(\mathbb{C})}$ \\ 1 Dental Materials Research Center, Health Research Institute, Babol University of Medical Sciences, Babol, Iran. \\ 2 Associate Professor, Oral Health Research Center, Health Research Institute, Babol University of Medical Sciences, \\ Babol, Iran \\ 3 Assistant Professor, Dental Materials Research Center, Health Research Institute, Babol University of Medical Sciences, \\ Babol, Iran. \\ * Correspondence: dr_ekhodadadi@yahoo.com;
}

Scopus Author ID 57191794677

Received: 7.05.2020; Revised: 23.05.2020; Accepted: 24.05.2020; Published: 27.05.2020

\begin{abstract}
The present study aimed to compare the micro-tensile bond strength of new and conventional glass-ionomers and Z350 flowable composite resin to sound and caries-affected dentin. Eighty extracted third molars were selected. Standard Cl I cavities were prepared on occlusal surfaces. Forty teeth were assigned to the sound tooth group, and in the remaining 40 teeth, carious lesions were produced using a laboratory technique. Then each group $(n=40)$ was subdivided into 5 groups $(n=8)$ in terms of the restorative material used (EQUIA® Forte, Ketac Molar, encapsulated and hand-mixed GC Fuji II LC glass-ionomers and Z350 flowable composite resin). The cavities were restored. The highest microtensile bond strength was recorded with Z350 flowable composite resin in sound dentin (29.65), and the lowest was recorded with GC Fuji II LC (powder, liquid) in affected dentin (7.88). Significant differences were detected in the micro-tensile bond strength between the 5 restorative material groups. The composite resin bond strength was the maximum and was significantly different from all the other groups. The micro-tensile bond strength was affected by the type of dentin; in this context, in all the restorative groups, the bond strength in sound dentin was significantly higher than that in affected dentin. The most frequent failure mode was adhesive in the sound and affected dentin.
\end{abstract}

Keywords: Glass-ionomer; bond strength; flowable composite.

(C) 2020 by the authors. This article is an open-access article distributed under the terms and conditions of the Creative Commons Attribution (CC BY) license (https://creativecommons.org/licenses/by/4.0/).

\section{Introduction}

Composite resins yield strong and esthetic restorations; however, they are very technique-sensitive and are very sensitive to moisture. It is very challenging to control moisture in an uncooperative child or in a child before the cooperative age. Glass-ionomers are less sensitive to moisture $[1,2]$. ART (alternative restorative treatment) is applied in very young and un-cooperative children or in patients with specific medical needs or when conventional cavity preparation or placement of restorative materials is not possible. In this technique, hand instruments or low-speed rotary instruments are used to remove caries, and glass-ionomer is used as the restorative material of choice [3-6].

Glass-ionomer cement (GIC) has been suggested as restorative materials for cervical lesions due to their ability to form chemical bonds with the enamel and dentin [4, 7]. Conventional glass-ionomers have some clinical limitations such as long setting time, the potential for dehydration during the early stages of setting, and surface roughness. To overcome 
these disadvantages, light-cured resin-modified glass-ionomer has been introduced, which have longer working time, faster setting, improved esthetic appearance, and higher translucency and initial strength compared to conventional glass-ionomers [8, 9]. Highviscosity glass-ionomers were developed with the aim to facilitate placement within the cavity without sticking to the instrument; these glass-ionomers have shorter setting time and lower initial solubility compared to resin-modified glass-ionomer [10-13].

Different glass-ionomers are available on the market to have different chemical and physical characteristics. The micro-tensile bond strength of these types of cement has a significant role in decreasing microleakage and the success of restorations with these materials. This is more important in relation to carious deciduous teeth in which minimal invasion is considered because the enamel and dentin are thin in these teeth, and aggressive removal of caries might negatively affect the bond strength $[14,15]$.

Several studies to date have evaluated conventional types of cement and their bond strength to dentin or enamel or carious deciduous teeth. However, little evidence is available in relation to glass-ionomer types of cement, especially on the new generation of CIS. The present study amid to compare the micro-tensile bond strength of new and conventional glassionomers (EQVIA® Forte, Ketac Molar, encapsulated, and hasnd-mixed Fuji II LC glassionomers) with sound and carious dentin.

\section{Materials and Methods}

\subsection{Laboratory approach.}

Eighty-third molar teeth, which had been extracted $<3$ months previously, were selected for the purpose of the present study. The teeth had no caries and visible cracks. The teeth were stored in a $0.2 \%$ thymol solution for 24 hours after the extraction, followed by cleaning with a periodontal curette and irrigation. Subsequently, the teeth were stored in normal saline solution, which was replaced on a weekly basis $[10,16,17]$. Standard Cl I cavities were prepared on the occlusal surfaces of the teeth, measuring $7 \mathrm{~mm}$ mesiodistally, $5 \mathrm{~mm}$ buccolingually, and $2 \mathrm{~mm}$ in depth, using a 0.12 fissure bur (JOTA Switzerland) in a high-speed handpiece under water spray by one operator. The burs were replaced by new ones after the preparation of 5 cavities. The cavity dimensions were measured with the use of a periodontal probe [10, 14].

Half of the samples $(n=40)$ underwent a cariogenic process in the dentin. First all, the tooth surfaces were covered with two layers of acid-resistant nail varnish except for the internal walls of the cavities. Then the teeth were immersed in $15 \mathrm{~mL}$ of a demineralizing solution (15 $\mathrm{mM} \mathrm{CaCl}_{2}, 0.9 \mathrm{mM} \mathrm{KH}_{2} \mathrm{PO}_{4}, 50 \mathrm{mM}$ acetic acid, $0.02 \% \mathrm{NaN}_{3}$ ) with $\mathrm{pH}=4.5$ at $37^{\circ} \mathrm{C}$ for 60 hours. Then the samples were stored in distilled water at $4^{\circ} \mathrm{C}$ [18]. Then both groups $(n=40)$ were subdivided into 5 groups $(n=8)$ in terms of the restorative material used. The cavities were restored according to the manufacturers' instructions.

The teeth were sectioned buccolingually and mesiodistally with the use of a diamond disk at a low speed using a cutting machine (Isomet, Buehler, Inc., Lake Bluff, IL, USA) at a right angle to the tooth surface to achieve cylinders with an approximate surface area of $1 \mathrm{~mm} 2$. The surface area of each sample was determined with the use of a digital Vernier to achieve an identical surface area at the interface. Then each sample was investigated under a stereomicroscope at $\times 40$. Samples with any defects were excluded from the study. Four complete and intact samples were achieved from each tooth. There were 32 sections in each subgroup, which were evaluated in relation to the micro-tensile bond strength [14, 19-22]. Each 
sample was connected to the special jig of the testing device (Shimadzu, Model AGS-X5 kN, Shimadzu Corporation, Kyoto, Japan) and underwent tension at a strain rate of $1 \mathrm{~mm} / \mathrm{min}$ until failure occurred. The force required to detach the restoration was reported in Newton $(\mathrm{N})$ by the device, and the micro-tensile bond strength was calculated in MPa by dividing the necessary force to detach the restoration by the adhesion surface area in $\mathrm{mm} 2$ [14].

\subsection{Statistical analysis.}

All the samples were evaluated for failure modes under a stereomicroscope at $\times 40$. Data were analyzed with SPSS 22. Independent t-test, one-way ANOVA and two-way ANOVA were used to compare micro-tensile bond strengths between the groups. Tukey tests were used for two-by-two comparisons. Statistical significance was set at $\mathrm{P}<0.05$.

\section{Results and Discussion}

This section may be divided by subheadings. It should provide a concise and precise description of the experimental results, their interpretation as well as the experimental conclusions that can be drawn.

Table 1 presents the means and standard deviations of micro-tensile bond strengths of the restorative materials to sound and affected dentin in MPa. The results showed that the dentin type affected micro-tensile bond strength, i.e., in all the restorative groups, the bond strength in sound dentin was significantly higher than that in affected dentin.

Table 1. The means and standard deviations of micro-tensile bond strength of restorative materials to sound and affected dentin.

\begin{tabular}{c|c|c|c|c|c}
\multirow{2}{*}{ Dentin type } & \multicolumn{5}{|c}{ Restorative material } \\
\cline { 2 - 6 } & EQUIA® Forte & $\begin{array}{c}\text { Encapsulated } \\
\text { Fuji II LC }\end{array}$ & $\begin{array}{c}\text { Hand-mixed Fuji } \\
\text { II }\end{array}$ & Ketac Molar & Filtek Z350 \\
\hline Sound dentin & $23.69 \pm 2.43$ & $21.83 \pm 2.15$ & $14.75 \pm 3.60$ & $19.7 \pm 2.56$ & $29.65 \pm 3.06$ \\
\hline $\begin{array}{c}\text { Affected } \\
\text { dentin }\end{array}$ & $13.63 \pm 2.57$ & $11.76 \pm 2.98$ & $7.86 \pm 3.08$ & $10.41 \pm 3.12$ & $22.02 \pm 2.96$ \\
\hline P-value & 0.00 & 0.00 & 0.00 & 0.00 & 0.00
\end{tabular}

The highest and lowest micro-tensile bond strength was were recorded with Z350 composite resin in sound dentin and hand-mixed GC Fuji II LC glass-ionomer in affected dentin. Significant differences were detected in bond strength between the 5 restorative materials (in both sound and affected dentin). Composite resin exhibited the highest microtensile bond strength in both the sound and affected dentin, with a significant difference from all the glass-ionomers. The micro-tensile bond strength of encapsulated glass-ionomer (in both sound and affected dentin) was considerably higher than that of hand-mixed glass-ionomer. In the encapsulated glass-ionomers (in both sound and affected dentin), the micro-tensile bond strength was as follows: EQUIA® Forte $<$ Encapsulated Fuji II LC $<$ Ketac Molar.

Table 2 presents the failure modes in the samples. The most frequent failure mode in the sound and affected dentin was adhesive. The highest frequency of cohesive failure was recorded with hand-mixed GC Fuji II LC glass-ionomer.

Table 2. Frequency distributions of failure modes.

\begin{tabular}{c|c|c|c|c}
\multirow{2}{*}{ Restorative material } & \multirow{2}{*}{ Dentin type } & \multicolumn{3}{c}{ Failure mode } \\
\cline { 3 - 5 } & & Adhesive & Mixed & Cohesive \\
\hline \multirow{2}{*}{ EQUIA $®$ Forte } & Sound dentin & 17 & 10 & 5 \\
\cline { 2 - 5 } & Affected dentin & 20 & 9 & 3 \\
\hline Encapsulated Fuji II LC & Sound dentin & 18 & 10 & 4 \\
\hline
\end{tabular}




\begin{tabular}{c|c|c|c|c}
\hline \multirow{2}{*}{\begin{tabular}{c}
\multirow{2}{*}{ Restorative material } \\
\cline { 2 - 4 }
\end{tabular}} & \multicolumn{3}{|c}{ Failure mode } \\
\cline { 2 - 5 } & & Adhesive & Mixed & Cohesive \\
\cline { 2 - 5 } Hand-mixed Fuji II & Affected dentin & 21 & 6 & 5 \\
\hline & Sound dentin & 18 & 6 & 8 \\
\cline { 2 - 5 } & Affected dentin & 15 & 7 & 10 \\
\hline \multirow{2}{*}{ Ketac Molar } & Sound dentin & 18 & 7 & 5 \\
\cline { 2 - 5 } & Affected dentin & 20 & 10 & 3 \\
\hline & Sound dentin & 19 & 11 & 1
\end{tabular}

In the present in vitro study, the micro-tensile bond strength of EQUIA ${ }^{\circledR}$ Forte encapsulated Fuji II LC, hand-mixed Fuji II LC, and Ketac Molar glass-ionomers was compared with that of Z350 flowable composite rein to sound and affected dentin. The results showed that the micro-tensile bond strength of different restorative materials was affected by the dentin substrate. In this context, the micro-tensile bond strength in all the restorative groups in sound dentin was higher than that in affected dentin, and the difference was statistically significant, consistent with the results of previous studies [14, 23, 24]. In the present study, instead of natural dentin caries, artificial caries was induced in dentin (demineralization of dentin with the use of acidic chemical solutions, which is similar to affected dentin).

Such a procedure is useful because the bonding surface is always smooth, and the severity of demineralization is standardized [14, 23, 25, 26].The chemical bond of glassionomer types of cement is mediated through ionic and polar bonds between hydroxyapatite and polycarboxylate radicals, and the resultant complex replaces calcium and phosphate ions. Since calcium ions are lost during demineralization in affected dentin, the odds of creation of bonds between the calcium ions of hydroxyapatite and the carboxyl groups polyalkenoic acid decreases compared to sound dentin $[14,19]$.

Costa et al. (2017) reported lower bond strength to composite resin in affected dentin despite the use of the etch-and-rinse system, compared to sound dentin, which was attributed to the weaker structure of demineralized affected dentin. This limits the penetration of the adhesive due to the obstruction of dentinal tubules with acid-resistant mineral deposits, creating an atypical hybrid layer (thinner than the hydride layer created in sound dentin [19]. In the present study, the highest micro-tensile bond strength was recorded with flowable composite resin (Filtek Z350 XT), which was significantly different from the resin-modified glassionomer groups, consistent with the results of previous studies [27, 28]. Papacchini et al. (2004) reported a lower bond strength of glass-ionomers compared to resin-based materials [28]. In addition, Xie et al. (2008) reported a higher bond strength for composite resin restorations compared to glass-ionomer restorations. They showed that the reason for this higher bond strength was the intimate adaptation of the restorative interface with dentin due to the formation of a hybrid layer in the intertubular dentin in the composite resin group [27].

In the present study, the micro-tensile bod strength of encapsulated glass-ionomer (in both sound and affected dentin) was signifi8cantly higher than that of hand-mixed Fuji II LC glass-ionomer. No study to date has compared the micro-tensile bond strength of encapsulated glass-ionomers and the hand-mixed varieties. However, Dowling et al. (2008) showed that encapsulated restorative glass-ionomer exhibited better mechanical properties compared to the hand-mixed varieties [29].

Tooth cavities are restored with encapsulated glass-ionomers using a special applier and special injection syringe. However, hand instruments are used for the restoration of cavities with hand-mixed glass-ionomer types, which might result in gaps at restoration-dentin interface due to the absence of intimate adaptation between the restorative material and the 
cavity walls because the restorative material might stick to hand instruments. In addition, in the encapsulated varieties, mixing is carried out in an amalgamator without manual intervention, while mixing in powder-and-liquid glass-ionomers is carried out manually, which might result in voids within the glass-ionomer bulk. Voids serve as stress points and increase the odds of cohesive failure with the glass-ionomer [30-32]. In the different encapsulated glassionomers (in both sound and affected dentin), the micro-tensile strength was as follows: Ketac Molar $<$ Encapsulated Fuji II LC $<$ EQUIA ${ }^{\circledR}$ Forte.

Poggio et al. (2014) evaluated the effects of several cavity conditioners (GC cavity conditioner, 37\% phosphoric acid and Cleafil SE Bond) on the shear bond strength of a conventional encapsulated glass-ionomer (Fuji IX GP Xtra) and an RMGI (Encapsulated Fuji II LC) to dentin. In all the conditioning techniques, the bond strength of Fuji IILC was significantly higher. An increase in the efficacy of the bond due to the use of a conditioner with Fuji II LC is due to the elimination of debris and relative demineralization, which increases the contact area, creation of microporosity and reaction with hydroxyapatite. They reported that preparation of the surface with polycarboxylic acid before restoration with Fuji II LC resulted in the formation of dentin resin tags at cement-dentin interface and formation of a hybrid-like layer. The hybrid layer increases the surface energy and formation of an interdiffusion zone between dentin and glass, finally creating micromechanical retention in association with a chemical bond to dentin. In the present study, a cavity conditioner was used in all the glassionomer groups. They also reported that Fuji II LC contains HEMA, which is a hydrophilic primer and results in the penetration of the monomers of the adhesive agent into demineralized dentin and an increase in bond strength through wetting the surface of collagen fibers and maintaining the collagen network in the expanded state by stiffening the collagen fibers [31].

EQUIA ${ }^{\circledR}$ Forte and Ketac Molar glass-ionomers do not contain HEMA. Although EQUIA ${ }^{\circledR}$ Forte glass-ionomer does not contain HEMA, the strength of its bond was higher than that of Fuji II LC glass-ionomer. Limited studies are available on the properties of this glass-ionomer. However, based on the manufacturer's claim, this glass-ionomer has improved properties, including a consistent bond to dentin. Considering a lack of significant differences in bond strength between Fuji II LC and EQUIA® Forte glass-ionomer and unavailability of similar studies, further studies are recommended on the subject. In the present study, glassionomers exhibited more cohesive failures compared to composite resin, consistent with the results of previous studies. Cohesive failures in glass-ionomers are explained by the fact that the cohesive strength of the glass-ionomer in question is less than its bond strength to dentin $[14,23]$. Inconsistent with a study by Burrow et al., who reported air inclusions in the glassionomer powder as stress concentration points, increasing the odds of cohesive failure in this restoration material [30], the most frequent cohesive failures were recorded with the handmixed glass-ionomer.

\section{Conclusions}

The results showed that the micro-tensile bond strength was affected by the dentin type. In this context, in all the restoration groups, the bond strength in sound dentin was significantly higher than that in affected dentin. The highest and lowest micro-tensile bond strengths were recorded with Z350 composite resin in sound dentin and with hand-mixed Fuji II LC glassionomer in affected dentin. The most frequent failure was made in the sound, and affected dentin was an adhesive failure. 


\section{Funding}

The present study was part of a postgraduate thesis by the corresponding author with grant number 2466.

\section{Acknowledgments}

The authors would like to thank the Dental Material Research Center of Babol University of Medical Sciences for the time and material supplements for the laboratory procedures.

\section{Conflicts of Interest}

\section{There is no conflict of interest.}

\section{References}

1. Cho, S.Y.; Cheng, A.C. A review of glass ionomer restorations in the primary dentition. J Can Dent Assoc 1999, 65, 491-5.

2. Pouyanfar, H.; Tabaii, E.S.; Aghazadeh, S.; Nobari, S.P.T.N.; Imani, M.M. Microtensile bond strength of composite to enamel using universal adhesive with/without acid etching compared to etch and rinse and selfetch bonding agents. Open Access Maced J Med Sci 2018, 6, https://doi.org/10.3889/oamjms.2018.427.

3. Babavalian, H.; Latifi, A.M.; Shokrgozar, M.A.; Bonakdar, S.; Tebyanian, H.; Shakeri, F. Cloning and expression of recombinant human platelet-derived growth factor-BB in Pichia Pink. Cell Mol Biol (Noisyle-grand) 2016, 62, 45-51, https://doi.org/10.14715/cmb/2016.62.8.8.

4. Soufdoost, R.S.; Yazdanian, M.; Tahmasebi, E.; Yazdanian, A.; Tebyanian, H.; Karami, A.; Nourani, M.R.; Panahi, Y. In vitro and in vivo evaluation of novel Tadalafil/ $\beta$-TCP/Collagen scaffold for bone regeneration: A rabbit critical-size calvarial defect study. Biocybern Biomed Eng 2019, 39, 789-796, https://doi.org/10.1016/j.bbe.2019.07.003.

5. Affairs, A.A.o.P.D.C.o.C. Policy on alternative restorative treatment (ART). Pediatr Dent 2005, 27.

6. Kasraei, S.; Yarmohamadi, E.; Ranjbaran Jahromi, P.; Akbarzadeh, M. Effect of 940nm Diode Laser Irradiation on Microtensile Bond Strength of an Etch and Rinse Adhesive (Single Bond 2) to dentin. J Dent (Shiraz) 2019, 20, 30-36, https://doi.org/10.30476/DENTJODS.2019.44560.

7. Powell, L.V.; Gordon, G.E.; Johnson, G.H. Clinical evaluation of direct esthetic restorations in cervical abrasion/erosion lesions: one-year results. Quintessence Int 1991, 22, 687-92.

8. Abd El Halim, S.; Zaki, D. Comparative evaluation of microleakage among three different glass ionomer types. Oper Dent 2011, 36, 36-42, https://doi.org/10.2341/10-123-lr.

9. Hamdan-Nassar, T.; Bellot-Arcis, C.; Paredes-Gallardo, V.; Garcia-Sanz, V.; Pascual-Moscardo, A.; Almerich-Silla, J.M.; Montiel-Company, J.M. Effect of 2\% Chlorhexidine Following Acid Etching on Microtensile Bond Strength of Resin Restorations: A Meta-Analysis. Medicina (Kaunas) 2019, 55, https://doi.org/10.3390/medicina55120769.

10. Ranjbar Omidi, B.; Madani, L.; Mirnejad Joybari, A.; Rashvand, E.; Oveisi, S. Effect of mechanical load cycling on the microleakage of three different glass ionomer restorations in class V cavities. JDM 2015, 28, 95-102, https://doi.org/10.18502/fid.v16i2.1365.

11. Daneshparvar, H.; Sadat-Shirazi, M.S.; Fekri, M.; Khalifeh, S.; Ziaie, A.; Esfahanizadeh, N.; Vousooghi, N.; Zarrindast, M.R. NMDA receptor subunits change in the prefrontal cortex of pure-opioid and multi-drug abusers: a post-mortem study. Eur Arch Psychiatry Clin Neurosci 2019, 269, 309-315, https://doi.org/10.1007/s00406-018-0900-8.

12. Esfahanizadeh, N.; Daneshparvar, P.; Takzaree, N.; Rezvan, M.; Daneshparvar, N. Histologic Evaluation of the Bone Regeneration Capacities of Bio-Oss and MinerOss X in Rabbit Calvarial Defects. Int J Periodontics Restorative Dent 2019, 39, e219-e227, https://doi.org/10.11607/prd.4181.

13. Esfahanizadeh, N.; Yousefi, H. Successful Implant Placement in a Case of Florid Cemento-Osseous Dysplasia: A Case Report and Literature Review. J Oral Implantol 2018, 44, 275-279, https://doi.org/10.1563/aaid-joi-D-17-00140.

14. Kucukyilmaz, E.; Savas, S.; Kavrik, F.; Yasa, B.; Botsali, M. Fluoride release/recharging ability and bond strength of glass ionomer cements to sound and caries-affected dentin. Niger. J. Clin. Pract 2017, 20, 226234, https://doi.org/10.4103/1119-3077.178917.

15. Zabeu, G.S.; Maenossono, R.M.; Scarcella, C.R.; Brianezzi, L.F.F.; Palma-Dibb, R.G.; Ishikiriama, S.K. Effect of diode laser irradiation on the bond strength of polymerized non-simplified adhesive systems after 12 months of water storage. J Appl Oral Sci 2019, 27, https://doi.org/10.1590/1678-7757-2018-0126. 
16. Khomarlou, N.; Aberoomand-Azar, P.; Lashgari, A.P.; Tebyanian, H.; Hakakian, A.; Ranjbar, R.; Ayatollahi, S.A. Essential oil composition and in vitro antibacterial activity of Chenopodium album subsp. striatum. Acta Biol Hung 2018, 69, 144-155, https://doi.org/10.1556/018.69.2018.2.4.

17. Taherian, A.; Fazilati, M.; Moghadam, A.T.; Tebyanian, H. Optimization of purification procedure for horse F(ab')2 antivenom against Androctonus crassicauda (Scorpion) venom. Trop J Pharm Res 2018, 17, https://doi.org/10.4314/tjpr.v17i3.4.

18. Saad, A.; Inoue, G.; Nikaido, T.; Ikeda, M.; Burrow, M.; Tagami, J. Microtensile Bond Strength of ResinModified Glass Ionomer Cement to Sound and Artificial Caries-Affected Root Dentin With Different Conditioning. Oper. Dent 2017, 42, 626-635, https://doi.org/10.2341/16-375-L.

19. Costa, A.R.; Garcia-Godoy, F.; Correr-Sobrinho, L.; Naves, L.Z.; Raposo, L.H.A.; Carvalho, F.G.D.; Sinhoreti, M.A.C.; Puppin-Rontani, R.M. Influence of different dentin substrate (caries-affected, cariesinfected, sound) on long-term $\mu$ TBS. Brazilian dental journal 2017, 28, 16-23, https://doi.org/10.1590/0103-6440201700879.

20. Mosaddad, S.A.; Tahmasebi, E.; Yazdanian, A.; Rezvani, M.B.; Seifalian, A.; Yazdanian, M.; Tebyanian, H. Oral microbial biofilms: an update. Eur J Clin Microbiol Infect Dis 2019, 38, 2005-2019, https://doi.org/10.1007/s10096-019-03641-9.

21. Seifi Kafshgari, H.; Yazdanian, M.; Ranjbar, R.; Tahmasebi, E.; Mirsaeed, S.; Tebyanian, H.; Ebrahimzadeh, M.A.; Goli, H.R. The effect of Citrullus colocynthis extracts on Streptococcus mutans, Candida albicans, normal gingival fibroblast and breast cancer cells. Biol Res 2019, 92, https://doi.org/10.4081/jbr.2019.8201.

22. Khojaste, M.; Yazdanian, M.; Tahmasebi, E.; Shokri, M.; Houshmand, B.; Shahbazi, R. Cell Toxicity and inhibitory effects of Cyperus rotundus extract on Streptococcus mutans, Aggregatibacter actinomycetemcomitans and Candida albicans. Eur J Transl Myol 2018, 28, 7917, https://doi.org/10.4081/ejtm.2018.7917.

23. Choi, K.; Oshida, Y.; Platt, J.A.; Cochran, M.A.; Matis, B.A.; Yi, K. Microtensile bond strength of glass ionomer cements to artificially created carious dentin. Oper Dent 2006, 31, 590-7, https://doi.org/10.2341/05-108.

24. Palma-Dibb, R.G.; de Castro, C.G.; Ramos, R.P.; Chimello, D.T.; Chinelatti, M.A. Bond strength of glassionomer cements to caries-affected dentin. J Adhes Dent 2003, 5, 57-62.

25. Alves, F.B.; Hesse, D.; Lenzi, T.L.; Guglielmi Cde, A.; Reis, A.; Loguercio, A.D.; Carvalho, T.S.; Raggio, D.P. The bonding of glass ionomer cements to caries-affected primary tooth dentin. Pediatr Dent 2013, 35, 320-4.

26. Heidari, M.F.; Arab, S.S.; Noroozi-Aghideh, A.; Tebyanian, H.; Latifi, A.M. Evaluation of the substitutions in 212, 342 and 215 amino acid positions in binding site of organophosphorus acid anhydrolase using the molecular docking and laboratory analysis. Bratisl Lek Listy 2019, 120, 139-143, https://doi.org/10.4149/BLL_2019_022.

27. Xie, H.; Zhang, F.; Wu, Y.; Chen, C.; Liu, W. Dentine bond strength and microleakage of flowable composite, compomer and glass ionomer cement. Aust Dent J 2008, 53, 325-31, https://doi.org/10.1111/j.1834-7819.2008.00074.x.

28. Papacchini, F.; Goracci, C.; Sadek, F.T.; Monticelli, F.; Garcia-Godoy, F.; Ferrari, M. Microtensile bond strength to ground enamel by glass-ionomers, resin-modified glass-ionomers, and resin composites used as pit and fissure sealants. J Dent 2005, 33, 459-67, https://doi.org/10.1016/j.jdent.2004.11.007.

29. Dowling, A.H.; Fleming, G.J. Is encapsulation of posterior glass-ionomer restoratives the solution to clinically induced variability introduced on mixing? Dent. Mater. J 2008, 24, 957-966, https://doi.org/10.1016/j.dental.2007.11.016.

30. Burrow, M.F.; Nopnakeepong, U.; Phrukkanon, S. A comparison of microtensile bond strengths of several dentin bonding systems to primary and permanent dentin. Dent Mater 2002, 18, 239-45, https://doi.org/10.1016/s0109-5641(01)00041-0.

31. Poggio, C.; Beltrami, R.; Scribante, A.; Colombo, M.; Lombardini, M. Effects of dentin surface treatments on shear bond strength of glass-ionomer cements. Ann Stomatol (Roma) 2014, 5, 15-22, https://doi.org/10.11138/ads/2014.5.1.015.

32. Haghani-Haghighi, H.; Mortazavian, A.M.; Hosseini, H.; Mohammadi, A.; Shojaee-Aliabadi, S.; KhosraviDarani, K.; Khorshidian, N. Method validation and determination of hydroxymethyl furfural (HMF) and furosine as indicators to recognize adulterated cow's pasteurized and sterilized milks made by partial reconstitution of skim milk powder. Biointerface Res. Appl. Chem 2019, 9, 3842-3848, https://doi.org/10.33263/briac92.842848.

33. Nagasarapu, M.R.; Konda, R. Development and validation of high performance thin layer chromatographic method for the determination of voglibose in bulk and their formulations. Lett. Appl. NanoBioScience 2020, 9, 1074-1078, https://doi.org/10.33263/LIANBS92.10741078. 